\title{
Pólos múltiplos geradores de viagens (PMGV)
}

\author{
Lenise Grando Goldner ${ }^{1}$; Diego Westphal'; \\ Ilce Marília D. Pinto de Freitas ${ }^{3}$; Denise Vaz de Carvalho Santos ${ }^{4}$
}

\begin{abstract}
Resumo: Denominam-se Pólos Múltiplos Geradores de Viagens (PMGVs) os conjuntos de estabelecimentos comerciais ou de serviços próximos entre si que formam "clusters" de atividades. O objetivo deste artigo é analisar as características das viagens por automóvel para PMGVs por meio de resultados encontrados em estudos de caso realizados nas cidades de Porto Alegre e Salvador. Utilizando a técnica de coleta de dados por questionários, foram levantadas informações sobre o perfil socioeconômico dos clientes e as principais características das viagens de acesso, visando a verificar se os usuários realizam viagens internas a esses "clusters" de atividades, bem como se utilizam mais de um estacionamento quando fazem a viagem por automóvel. Os resultados do estudo buscam iniciar as discussões sobre o comportamento das viagens em PMGVs brasileiros e apresentar os primeiros parâmetros para os fatores de atenuação das viagens que possam ser utilizados em estudos de avaliação de impactos no sistema viário do entorno desses empreendimentos.
\end{abstract}

\begin{abstract}
Trip Generator Multi-pole (TGMP) is a set of shops and services establishments close to each other, forming a "cluster" of activities. This paper analyzes the attraction characteristics of trips made to/from/within this type of poles made by car. This research studies cases in two Brazilian cities: Porto Alegre and Salvador. Using the technique of data collection through questionnaires, information has been obtained about the socio-economic profile of customers, the main characteristics of access trips in order to establish whether the respondent performs internal travel to these clusters of activities as well as whether they use more than one parking area, when they travel by car. The results of these studies seek to initiate discussions about the behavior of Brazilian TGMP travels and to present the initial parameters for the mitigating factors of trips that can be used in a study of impact assessment in the road system surrounding these developments.
\end{abstract}

\section{INTRODUÇÃO}

Os Pólos Geradores de Viagens (PGV), dos mais diferentes tipos, foram bastante estudados no Brasil e no exterior. Esses estudos analisam o PGV isoladamente, buscando quantificar as viagens geradas e os impactos das mesmas no sistema viário do entorno. Grande parte da produção da Rede Ibero-americana de Estudos em Pólos Geradores de Viagens (REDPGV) é dedicada ao tema, conforme pode ser observado no portal da mesma na internet.

Nos últimos anos, entretanto, surgiu uma tendência de concentração de PGVs em locais próximos, formando um "cluster de atividades", que potencializam a quantidade de viagens para essa região que necessita de estudos adicionais sobre os impactos causados no sistema viário. Assim, surge o conceito de desenvolvimento de uso múltiplo, os quais serão denominados, neste trabalho, de Pólos Múltiplos Geradores de Via-

\footnotetext{
${ }^{1}$ Lenise Grando Goldner, Programa de Pós-Graduação em Engenharia Civil, Universidade Federal de Santa Catarina, Florianópolis, SC, Brasil. (e-mail: lenise@ecv.ufsc.br).

${ }^{2}$ Diego Westphal, Programa de Pós-Graduação em Engenharia Civil, Universidade Federal de Santa Catarina, Florianópolis, SC, Brasil. (e-mail: diegow@matrix.com.br).

${ }^{3}$ Ilce Marília D. Pinto de Freitas, Mestrado de Engenharia Ambiental Urbana, Universidade Federal da Bahia, Salvador, BA, Brasil. (e-mail: ilce_marilia@hotmail.com).

${ }^{4}$ Denise Vaz de Carvalho Santos, Mestrado de Engenharia Ambiental Urbana, Universidade Federal da Bahia, Salvador, BA, Brasil. (e-mail: denisevaz@gmail.com).
}

Manuscrito recebido em 25/1/2010 e aprovado para publicação em 4/3/2010. Este artigo é parte de TRANSPORTES, volume XVIII, número 1, março de 2010. ISSN: 2237-1346 (online). gens (PMGVs).

Embora não haja consenso entre diferentes pesquisadores sobre o conceito de desenvolvimento de uso múltiplo em relação ao conceito de desenvolvimento de uso misto, o ITE - Institute of Transportation Engineering - apresentou em 2004 um método de análise para os mesmos, na sua publicação Trip Generation Handbook.

Sobre uso misto, encontraram-se estudos bem mais antigos, como o do Colorado/Wyoming Section Technical Committee - Trip Generation (1987), que já buscava pesquisar os fatores de atenuação nas viagens externas em função das viagens internas entre os usos do solo que formavam o uso misto.

Sobre desenvolvimento de uso múltiplo, Goldner e Schmitz (2010) realizaram uma investigação para o Parque Comercial Montigalá, na região metropolitana de Barcelona, na Espanha, com dados coletados em 2007, por meio de um método simplificado, considerando apenas dois empreendimentos comerciais dentre aqueles que formavam o cluster de atividades.

No Brasil, estudos sobre desenvolvimento de uso múltiplo são ainda embrionários. Em 2009, foram coletados dados de um PMGV em Porto Alegre (Goldner e Westphal, 2010) sobre uma área constituída por um hipermercado e um shopping center, e em 2010 em Salvador (Freitas e Santos, 2010) sobre uma área construída por uma instituição de ensino superior e um shopping center. Esses estudos tiveram um caráter exploratório, a partir de bases empíricas e visavam a entender o comportamento da demanda de viagem de PMGVs. 
O objetivo deste artigo é, portanto, apresentar os resultados encontrados nos estudos realizados em Porto Alegre e Salvador, citados anteriormente, buscando iniciar as discussões sobre o comportamento das viagens em PMGVs brasileiros e apresentar os primeiros parâmetros para os fatores de atenuação nas viagens externas que possam ser utilizados em estudo de avaliação de impactos desses empreendimentos no sistema viário.

\section{FUNDAMENTAÇÃO TEÓRICA}

Segundo Datta e Schattler (2010), com base na publicação Trip Generation do ITE (2008), um desenvolvimento de uso múltiplo consiste em um empreendimento que inclui duas ou mais categorias de uso do solo em que as viagens podem ser feitas sem usar o sistema viário externo. Esses empreendimentos atraem tipicamente uma quantidade significativa de viagens de múltiplos propósitos.

Pode haver diversas interpretações para o que se constitui um desenvolvimento de uso múltiplo no campo do planejamento de transportes. Por exemplo, tratar-se de uma combinação de diferentes tipos de uso do solo dentro de uma área definida. Para o ITE, entretanto, o desenvolvimento de uso múltiplo tem uma definição específica: um único projeto imobiliário que consiste em duas ou mais classificações de uso do solo, entre as quais se podem realizar viagens sem o uso do sistema viário externo.

O termo desenvolvimento de uso múltiplo não deve ser confundido com desenvolvimento de uso misto (MXD), segundo os autores. Para o Urban Land Institute (ULI), que é uma organização de pesquisa sobre o uso do solo, sem fins lucrativos, o desenvolvimento de uso misto significa: (1) um projeto imobiliário relativamente de grande escala caracterizado por: três ou mais significantes usos revenue-producing (como por exemplo, comércio, escritórios, residencial, hotel e de recreação - os quais, quando bem planejados, se apóiam mutuamente); (2) componentes do projeto com integrações físicas e funcionais significantes; (3) desenvolvimento em conformidade com um plano coerente (que estipula freqüentemente o tipo e a escala dos usos, as densidades permitidas e itens associados).

Nas metodologias convencionais, ao se estimar as viagens geradas pelo empreendimento de uso múltiplo, são calculadas taxas da geração de viagens e equações para cada um dos usos de solo individualmente e posteriormente são adicionados juntos. Isso é possível desde que a maioria das taxas e as equações de geração de viagens sejam desenvolvidas baseadas nos dados coletados para um único uso e de forma independente. Entretanto, dessa forma, a geração de viagem interna dentro desses desenvolvimentos não será conhecida. Em conseqüência, a geração total de viagens dos veículos que chegam e que partem do local de uso múltiplo pode ser superestimada quando forem somadas as viagens geradas por cada uso de solo individual.

Algumas viagens são feitas aos vários usos de solo dentro do desenvolvimento multiuso (ou uso múltiplo) pelas vias internas e não necessitam de veículos para usar o sistema de ruas adjacentes. Uma taxa interna de captação pode ser usada na análise da geração de viagens para esclarecer a geração interna de viagens. A taxa interna da captação pode ser definida como o percentual da redução aplicada às estimativas da geração de viagens para uso de solos individuais e esclarece as viagens internas ao local. Esses fatores da redução são aplicados externamente às entradas de automóveis no local e às vias e interseções adjacentes. Devem ser descontados antes de aplicar a redução devido às viagens do tráfego de passagem.

Bochner et al. (2010) consideram que o uso misto é um novo tipo de desenvolvimento de uso múltiplo que surgiu nos últimos anos. Eles estudaram um melhoramento na estimativa da captura de viagens internas para desenvolvimentos de uso misto, a partir do capítulo 7 do ITE Trip Generation Handbook (2004). Reconhecendo as limitações do método do ITE, o National Cooperative Highway Research Program (NCRP) iniciou o projeto 8-51, em 2005, para melhorar a metodologia utilizada. Nesse estudo, foram utilizados levantamentos de dados existentes em estudos anteriores mais levantamentos em três adicionais MXD.

O método de estimativa do NCRP é baseado nos procedimentos do ITE, mas expandido para cobrir o período de pico da manhã e da tarde, seis principais usos mais freqüentemente encontrados em um MXD e a proximidade de interação entre os usos do solo. Os seguintes produtos foram obtidos: viagens internas de pessoas nos picos da manhã e da tarde por uso do solo na forma de origem-destino; percentagem de captura interna para viagens pessoais; e viagens internas de pessoas nos picos da manhã e da tarde de entrada e de saída (viagens de e para o desenvolvimento sendo analisado) por modo de transporte (veículos, transporte coletivo e não motorizados).

$\mathrm{Na}$ seqüência do artigo, apresentam-se os principais resultados obtidos nos dois estudos de caso realizados (Porto Alegre e Salvador) que se enquadram no conceito de PMGV utilizado neste estudo e as demais informações referentes aos empreendimentos que o formam, bem como o método utilizado na pesquisa. 


\section{RESULTADOS OBTIDOS}

\subsection{Estudo de caso em Porto Alegre - Rio Grande do Sul}

Escolheu-se realizar um estudo sobre PMGVs na cidade de Porto Alegre pela proximidade geográfica com Florianópolis, onde foi feito o planejamento da pesquisa, tratamento e análise dos dados, e pela possibilidade de colaboração de alunos da UFRGS nos levantamentos, reduzindo os custos dos mesmos.

Dentre os PMGVs existentes na cidade de Porto Alegre, o de maior importância, pela magnitude do impacto causado no sistema viário, localiza-se no Bairro Três Figueras e é constituído por um hipermercado de $27.590,86 \mathrm{~m}^{2}$ de área de vendas e um shopping center de $39.115 \mathrm{~m}^{2}$ de Área Bruta Locável (ver Figura 1). Os contatos foram feitos com as duas administrações dos empreendimentos, sendo que somente o shopping center permitiu a realização dos levantamentos, condicionado ao sigilo quanto ao nome do estabelecimento, bem como restringindo os dias de semana da pesquisa entre segunda e quinta-feira.

Devido ao fato das metodologias brasileiras de avaliação de impacto terem sido desenvolvidas para as viagens de automóvel, bem como os seus principais modelos de geração de viagens, optou-se por entrevistar os clientes que vinham ao shopping de automóvel, nas entradas principais do empreendimento.

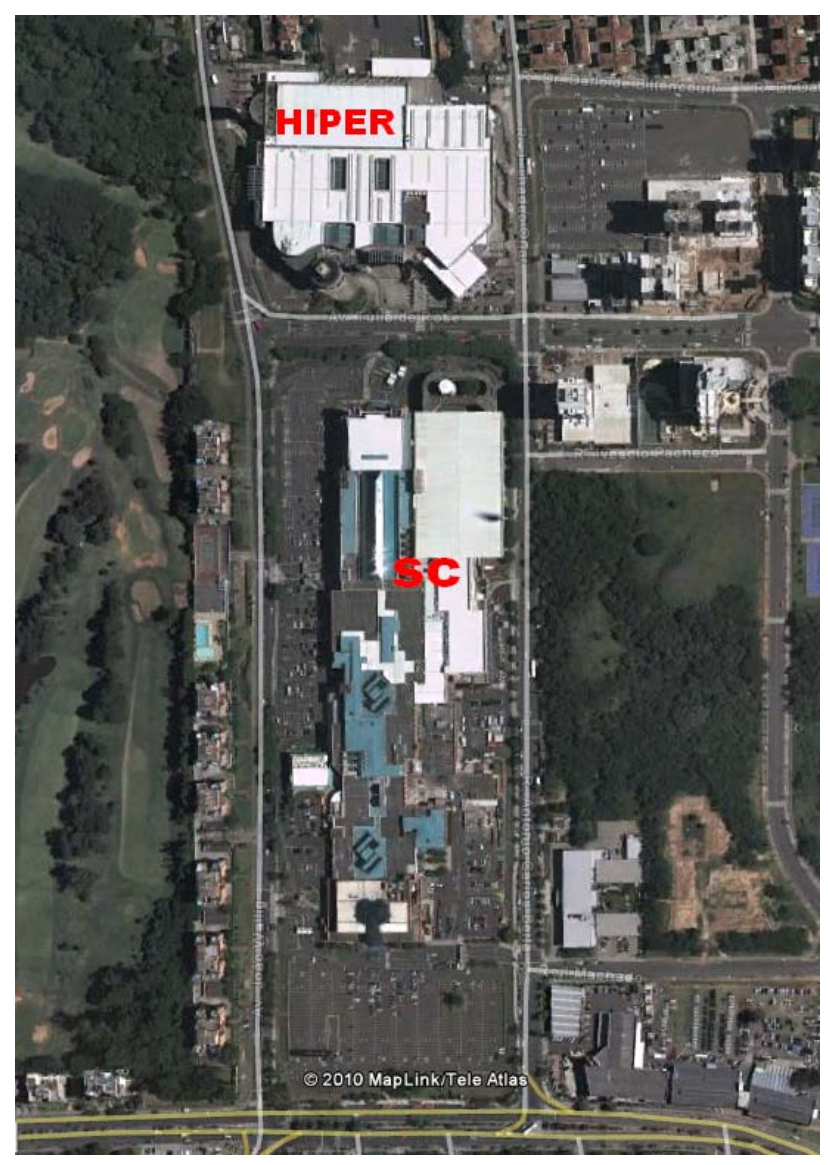

Figura 1. Localização do Shopping Center e Hipermercado em Porto Alegre [Fonte: Google Earth]

\subsubsection{Amostra}

As entrevistas foram realizadas nos dias 05, 06, 07 e 08 de dezembro de 2009, de segunda a quinta-feira, das 10:00 às 20:00 h nas entradas do shopping center. Nesse período, foram levantados dados socioeconômicos e informações referentes às viagens utilizando como base um questionário que continha 17 itens. A entrevista era realizada somente com pessoas que vieram ao shopping center de automóvel e utilizavam o estacionamento do próprio shopping ou as vias do entorno. O total de entrevistas realizadas foi de 255 e as informações obtidas foram: sexo, idade e escolaridade dos entrevistados, meio de transporte utilizado para acesso e egresso ao shopping, lugar de origem e destino da viagem, bairro ou cidade onde se situavam, tempo de viagem, motivo da viagem, via principal de acesso, se visitou ou visitaria o hipermercado ao lado, se utilizaria outro estacionamento além do pertencente ao shopping naquele dia, categoria da viagem e tempo de permanência no shopping.

\subsubsection{Perfil socioeconômico}

Com as entrevistas, levantou-se um perfil socioeconômico do usuário do estacionamento do shopping center. A maioria dos entrevistados - 55,29\% - era do sexo feminino. A faixa etária predominante foi dos 25 aos 34 anos, representando $33,33 \%$ da amostra. A idade média, obtida pela média ponderada das classes, foi de 41 anos. $\mathrm{O}$ grau de escolaridade predominante na amostra foi o ensino superior completo, representando $45,49 \%$ da amostra, seguido pelo segundo grau completo e pós-graduação, ambos com $18 \%$.

\subsubsection{Características das viagens}

Como só foram entrevistados os clientes que vieram ao shopping de automóvel, só havia duas alternativas de escolha, os que eram condutores e os que eram passageiros. A predominância foi daqueles que vieram ao shopping conduzindo o veículo, o que representou $91,76 \%$ da amostra, como foi observado na Tabela 1.

Tabela 1. Meio de transporte utilizado

\begin{tabular}{lcc}
\hline \multicolumn{1}{c}{ Meio utilizado } & Freqüência & $\%$ \\
\hline $\begin{array}{l}\text { Automóvel como con- } \\
\text { dutor }\end{array}$ & 234 & $91,76 \%$ \\
\hline $\begin{array}{l}\text { Automóvel como pas- } \\
\text { sageiro }\end{array}$ & 21 & $8,24 \%$ \\
\hline & $\Sigma=255$ & $\Sigma=100,00 \%$ \\
\hline
\end{tabular}

A maioria das viagens está dentro da isócrona dos 10 minutos, correspondente a $43,53 \%$, e na medida em que aumenta o tempo de viagem, diminui a quantidade de viagens. Verificou-se também que o tempo médio de viagem de acesso foi de 17,16 minutos, o que condiz com as informações obtidas, pois $76,47 \%$ das viagens tiveram duração menor ou igual a vinte minutos. 
A grande maioria das viagens originou-se na residência e no trabalho, respectivamente $47,84 \%$ e $32,16 \%$, como pode ser observado na Tabela 2 .

Tabela 2. Lugar de Origem

\begin{tabular}{|c|c|c|}
\hline Lugar de onde saiu & Freqüência & $\%$ \\
\hline Residência & 122 & $47,84 \%$ \\
\hline Trabalho & 82 & $32,16 \%$ \\
\hline Outros & 15 & $5,88 \%$ \\
\hline Compras & 11 & $4,31 \%$ \\
\hline $\begin{array}{l}\text { Consultas médicas, o- } \\
\text { dontológicas }\end{array}$ & 11 & $4,31 \%$ \\
\hline Estudo & 8 & $3,14 \%$ \\
\hline Lazer & 4 & $1,57 \%$ \\
\hline \multirow[t]{2}{*}{ Visita } & 2 & $0,78 \%$ \\
\hline & $\Sigma=255$ & $\Sigma=100,00 \%$ \\
\hline
\end{tabular}

A opção de destino que predominou foi a residência, sendo que essa opção correspondeu a $56,47 \%$ da amostra, seguido pelo trabalho com $23,53 \%$,

Observou-se que houve uma grande variedade nos bairros e cidades de origem das viagens, com uma pequena predominância do bairro de Petrópolis, correspondendo a $8,30 \%$ do total. Os bairros onde mais se originaram viagens situam-se na própria cidade de Porto Alegre, representando $89 \%$ do total.

A pergunta a seguir foi incorporada ao questionário com o objetivo de verificar as viagens internas dentro do PMGV. O hipermercado estudado situa-se próximo ao shopping center pesquisado e pode ser acessado com facilidade a pé. Observou-se que $14,51 \%$ dos entrevistados aproveitaram a viagem ao shopping para também visitar o hipermercado, conforme apresentado na Tabela 3.

Tabela 3. Visitou ou visitará o Hipermercado

\begin{tabular}{ccc}
\hline Opção & Freqüência & \% \\
\hline Sim & 37 & $14,51 \%$ \\
\hline Não & 218 & $85,49 \%$ \\
\hline & $\Sigma=255$ & $\Sigma=100,00 \%$ \\
\hline
\end{tabular}

Como já foi assinalado, neste trabalho adotou-se como o objeto de estudo as viagens por automóvel, devido ao fato de as metodologias brasileiras de avaliação de impacto darem ênfase a esse modo de transporte. Desta forma, procurou-se verificar se os clientes que vinham ao shopping de automóvel trocavam de estacionamento ao visitarem o hipermercado. Esse percentual representaria o fator de atenuação das viagens. Observou-se que esse índice é bastante baixo $(1,19 \%)$, facilmente explicado pela facilidade de acesso a pé entre os empreendimentos, bem como pela dupla cobrança de estacionamento, o que oneraria a viagem.

Por outro lado, a partir dessa pergunta, observou-se outra questão importante, sobre as viagens de auto- móvel dos que estacionam na rua, que não são previstas nos modelos de geração de viagens nas estimativas que são normalmente feitas e que representam um fator de agravamento do impacto. Esse percentual foi de 10,71\%, conforme apresentado na Tabela 4 .

Tabela 4. Estacionamentos utilizados

\begin{tabular}{lcc}
\hline \multicolumn{1}{c}{ Opção } & Freqüência & $\%$ \\
\hline do shopping center & 222 & $88,10 \%$ \\
\hline rua & 27 & $10,71 \%$ \\
\hline $\begin{array}{l}\text { Ambos - do shopping } \\
\text { center e do hipermercado }\end{array}$ & 3 & $1,19 \%$ \\
\hline & $\Sigma=252$ & $\Sigma=100,00 \%$ \\
\hline
\end{tabular}

Outra informação levantada na entrevista refere-se ao tempo de permanência do cliente no shopping center, que representa também o tempo de permanência na vaga de estacionamento. $\mathrm{O}$ valor médio encontrado foi de 1 h e 33 minutos.

\subsection{Estudo de caso em Salvador - Bahia}

No estudo de caso em Salvador, a escolha do Pólo Múltiplo Gerador de Viagens constituído por um shopping center e uma instituição de ensino superior foi determinada principalmente em função da localização desses empreendimentos. Os empreendimentos selecionados - o Shopping Paralela e a Faculdade de Tecnologia e Ciência (FTC) - estão situados na área de maior expansão imobiliária da cidade. $\mathrm{O}$ acesso imediato a eles se dá por uma via marginal da Avenida Luiz Viana Filho (ver Figura 2), uma importante avenida que conecta o atual centro comercial da cidade ao aeroporto, aos municípios do litoral norte da Bahia e ao Pólo Industrial de Camaçari.

A área onde estão localizados o Shopping Paralela e a FTC tem ocupação ainda recente, observando-se, entretanto, crescente implantação de empreendimentos comerciais e de serviços, faculdades e condomínios residenciais ao longo da Av. Luiz Viana Filho.

Outro motivo que concorreu para a escolha desses empreendimentos como estudo de caso é que o Shopping Paralela foi inaugurado recentemente, no ano de 2009, e para o seu processo de licenciamento foi elaborado um Estudo de Impacto de Vizinhança o $(E I V)^{1}$. As informações contidas nesse documento poderão embasar uma análise comparativa entre as viagens geradas previstas para o PGV de forma isolada e as viagens realizadas, utilizando o conceito de desenvolvimento dos Pólos Múltiplos Geradores de Viagens (PMGV).

\footnotetext{
${ }^{1}$ A Lei Federal 10.257/2001, conhecida como Estatuto da Cidade (EC), prevê a obrigatoriedade de elaboração do Estudo de Impacto de Vizinhança (EIV) para empreendimentos que a lei municipal considerar como promotores de mudanças significativas no perfil da região onde se instalar (artigos 36 a 38).
} 


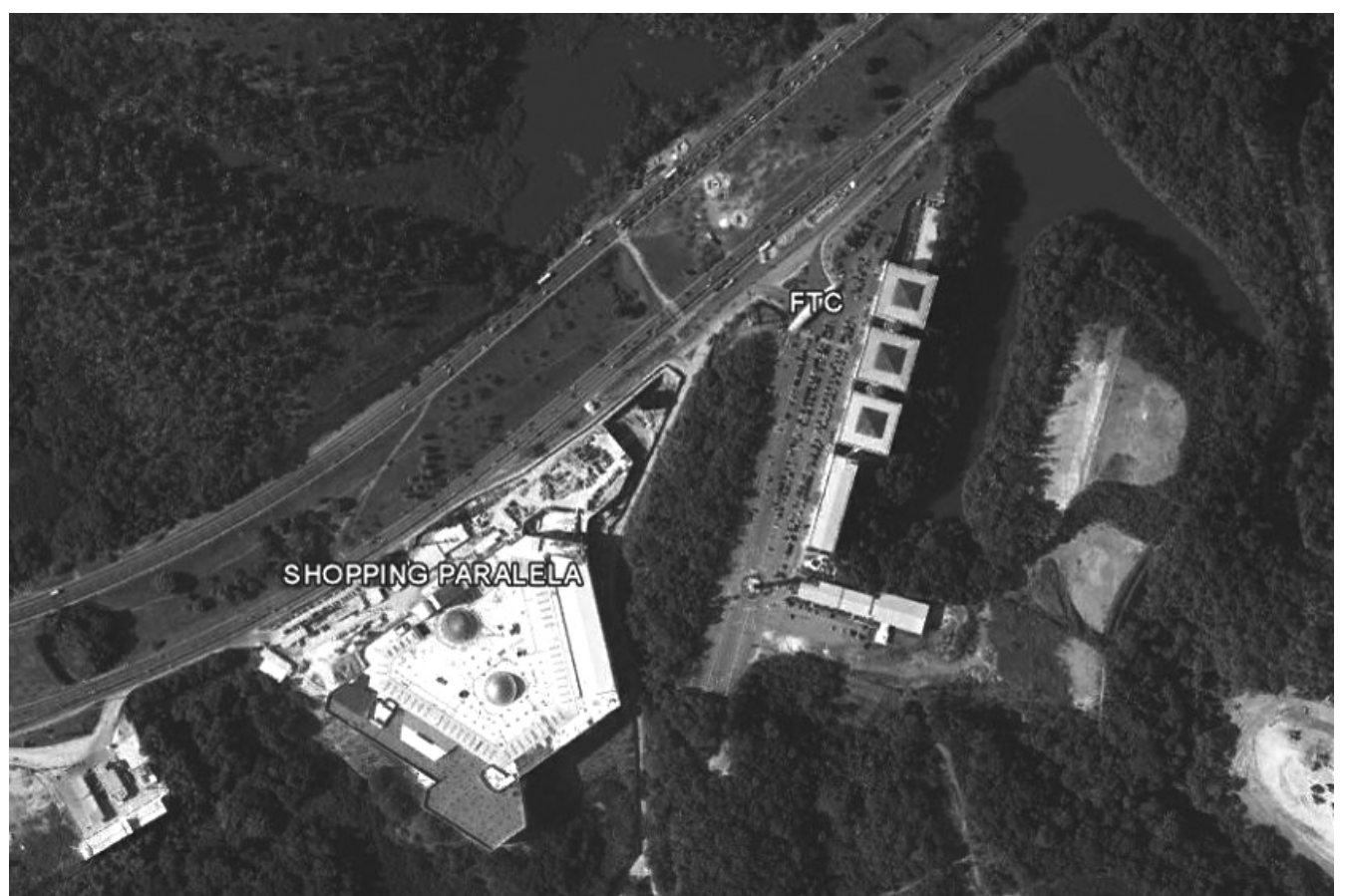

Figura 2. Situação do Shopping Paralela e da FTC [Fonte: Google Earth]

\subsubsection{Aspectos gerais do PMGV e do sistema viário do entorno}

O Shopping Paralela e a Instituição de Ensino Superior (IES), denominada FTC, localizam-se em terreno lindeiro à Avenida Luiz Viana Filho - avenida de trânsito rápido cuja função é realizar a articulação entre as macrozonas que compõem o município de Salvador e deste com outros que compõem a sua Região Metropolitana.

Essa avenida é composta de duas pistas, uma para cada sentido de tráfego, com quatro faixas de tráfego por sentido, por onde trafega, atualmente, um expressivo volume tanto no que se refere aos veículos particulares quanto ao transporte público coletivo. A circulação de pedestres em torno do local onde estão implantados os empreendimentos é intensa em função do uso do solo lindeiro, porém, não há infraestrutura adequada para esses usuários.

O Shopping Paralela é um empreendimento com $119.339 \mathrm{~m}^{2}$ de área construída, $40.000 \mathrm{~m}^{2}$ de ABL (Área Bruta Locável), 433 unidades comerciais (400 lojas satélites, 22 mega stores e 5 lojas âncoras), cinemas e Serviço de Atendimento ao Cliente (SAC), com cartório e confecção de documentos (Registro Geral, CPF e Passaporte).

A instituição de ensino que compõe o pólo múltiplo é a FTC, que possui cerca de $28.000 \mathrm{~m}^{2}$ de área construída, cerca de 2.000 vagas de estacionamento, mais de 6.000 alunos em 26 cursos de graduação e pósgraduação, 838 funcionários e aproximadamente 600 professores. O empreendimento conta com algumas atividades que atraem viagens também do público externo, como Clínicas de Fisioterapia, Nutrição e Odontologia, Núcleo de Prática Jurídica, biblioteca e uma academia de ginástica com $600 \mathrm{~m}^{2}$.

Da mesma forma que no estudo do caso de Porto Alegre, os contatos foram feitos com a administração dos dois empreendimentos, porém, somente o Shopping Center permitiu a aplicação dos questionários, oferecendo todas as informações pedidas e condições para que as entrevistas fossem realizadas da melhor forma possível.

\subsubsection{Amostra}

As entrevistas foram realizadas no período de 13 a 17 de setembro de 2010, de segunda a sexta-feira, das 10:00 às 21:00 h nas entradas do Shopping Center Paralela. A escolha do período e o horário de pesquisa no shopping foram decididos de forma que houvesse compatibilização com os horários de aulas da FTC. Nesse período, foram levantados dados socioeconômicos e informações referentes às viagens, utilizando como base um questionário semelhante ao utilizado no caso de Porto Alegre, com 16 itens. Também foi adotado, como em Porto Alegre, o procedimento de se realizar as entrevistas somente com pessoas que foram ao shopping center de automóvel e utilizaram os estacionamentos do próprio shopping (internos e da área externa). O total de entrevistas realizadas foi de 2670 e as informações obtidas foram: sexo, idade e escolaridade dos entrevistados, meio de transporte utilizado para acesso e egresso ao shopping, lugar de origem e destino da viagem, bairro ou cidade onde se situavam, tempo de viagem, motivo da viagem, via principal de acesso, se a viagem tinha origem ou destino na faculdade ao lado, se utilizaria outro estacionamento além do pertencente ao shopping naquele dia, categoria da viagem e tempo de permanência no shopping. 


\subsubsection{Perfil Socioeconômico}

Com as entrevistas, levantou-se o perfil socioeconômico dos usuários do Shopping Paralela. A maioria dos entrevistados, $56,72 \%$, era do sexo feminino. A faixa etária predominante foi dos 25 aos 34 anos, representando $31,31 \%$ da amostra, seguida da faixa de 35 aos 44 anos com $22,66 \%$.

$\mathrm{O}$ grau de escolaridade predominante na amostra foi ensino superior completo, representando $32,46 \%$ da amostra, seguido por segundo grau completo com $23,15 \%$, superior incompleto com $22,74 \%$ e pósgraduação com $15,42 \%$ do total.

\subsubsection{Características das viagens}

Conforme já comentado anteriormente, nos dois estudos de caso só foram entrevistados os clientes que vieram ao shopping de automóvel. Diante dessa premissa, só havia duas alternativas de escolha dos tipos de usuários: os que eram condutores e os que eram passageiros. A predominância foi por aqueles que vieram ao shopping conduzindo o veículo, o que representou $91,76 \%$ da amostra, como foi observado na Tabela 5 .

Tabela 5. Meio de transporte utilizado

\begin{tabular}{lcc}
\hline \multicolumn{1}{c}{ Meio utilizado } & Freqüência & $\%$ \\
\hline $\begin{array}{l}\text { Automóvel como } \\
\text { condutor }\end{array}$ & 1996 & $75,01 \%$ \\
\hline $\begin{array}{l}\text { Automóvel como } \\
\text { passageiro }\end{array}$ & 665 & $24,99 \%$ \\
\hline \multicolumn{2}{c}{$\Sigma=2661^{2}$} & $\Sigma=100,00 \%$ \\
\hline${ }^{2}$ Total de questionários válidos.
\end{tabular}

Em relação ao motivo de viagem, a Tabela 6 apresenta as principais respostas dos usuários entrevistados.

Tabela 6. Motivo de Viagem

\begin{tabular}{lcc}
\hline \multicolumn{1}{c}{ Motivo de Viagem } & Freqüência & $\%$ \\
\hline Compras & 52 & $1,95 \%$ \\
\hline Passeio & 35 & $1,31 \%$ \\
\hline Cinema & 14 & $0,52 \%$ \\
\hline Alimentação & 27 & $1,01 \%$ \\
\hline Trabalho & 14 & $0,52 \%$ \\
\hline SAC & 12 & $0,45 \%$ \\
\hline Outros ${ }^{4}$ & 265 & $9,93 \%$ \\
\hline Compras + Outros & 721 & $27,00 \%$ \\
\hline Passeio+ Outros & 330 & $12,36 \%$ \\
\hline Cinema + Outros & 239 & $8,95 \%$ \\
\hline Alimentação + Outros & 303 & $11,35 \%$ \\
\hline Trabalho + Outros & 234 & $8,76 \%$ \\
\hline SAC + Outros & 170 & $6,37 \%$ \\
\hline Demais combinações & 254 & $9,52 \%$ \\
\hline${ }^{3}$ Total de questionários válidos. & $\Sigma=2670^{5}$ & $\Sigma=100,00 \%$ \\
\hline${ }^{3}$ SAC: Serviço de Atendimento ao Usuário. & \\
\hline pagamentos, bancos, acompanhar pessoas, cursos e serviços. & \\
\hline
\end{tabular}

A Tabela 6 demonstra que as combinações de motivos de viagens, tais como compras + outros $(27,00 \%)$ ou alimentação + outros $(12,36 \%)$, apresentam maiores percentuais que motivos isolados, tais como compras $(1,95 \%)$ ou alimentação $(1,01 \%)$.

A área de influência representa um espaço geográfico para qual parte da população pode ser atraída pelo empreendimento. Para limitar a área de influência pelo traçado das isócronas, são considerados vários fatores que podem influenciar no poder de atração do empreendimento, tais como polarização do local, condições e formas de acesso e tempo de percurso. Na pesquisa realizada para o Shopping Paralela, pôde-se observar que a maioria das viagens ficou localizada dentro da isócrona de 15 a 30 minutos, correspondente a $34,22 \%$. Verificou-se também que existe uma significativa quantidade de viagens na faixa de 5 a 10 minutos $(20,82 \%)$. O tempo médio de viagem de acesso ao Shopping foi de 22 minutos, em concordância com as informações obtidas, pois $82,67 \%$ das viagens tiveram duração de até 30 minutos.

A grande maioria das viagens originou-se na residência e no trabalho: $50,11 \%$ e $32,16 \%$, respectivamente, como pode ser observado na Tabela 7 .

Tabela 7. Lugar de Origem

\begin{tabular}{|c|c|c|}
\hline Lugar de onde saiu & Freqüência & $\%$ \\
\hline Residência & 1337 & $50,11 \%$ \\
\hline Trabalho & 858 & $32,16 \%$ \\
\hline Compras & 62 & $2,32 \%$ \\
\hline $\begin{array}{l}\text { Consultas médicas, } \\
\text { odontológicas }\end{array}$ & 39 & $1,46 \%$ \\
\hline Estudo & 28 & $1,05 \%$ \\
\hline Lazer & 58 & $2,17 \%$ \\
\hline Visita & 34 & $1,27 \%$ \\
\hline FTC & 77 & $2,89 \%$ \\
\hline UNIJORGE $^{6}$ & 31 & $1,16 \%$ \\
\hline \multirow[t]{2}{*}{ Outros } & 144 & $5,40 \%$ \\
\hline & $\Sigma=2668^{7}$ & $\Sigma=100,00 \%$ \\
\hline
\end{tabular}

Analisar a Área de Influência de um PMGV é um aspecto que necessita de um maior aprofundamento. No estudo de caso de Salvador, quando se analisam as origens das viagens, observa-se que elas se distribuem por uma grande variedade de bairros da própria cidade de Salvador (89\%) e da Região Metropolitana $(10,63 \%)$, apresentando pequena incidência as viagens originadas em cidades localizadas em outros municípios do estado da Bahia $(0,37 \%)$.

No caso da opção de destino, ficou constatado que a opção residência também foi a predominante, a qual correspondeu a $67,42 \%$ da amostra, seguida por trabalho com $17,70 \%$, como pode ser observado na Tabela 8 . 
Tabela 8. Lugar de Destino

\begin{tabular}{lcc}
\hline $\begin{array}{c}\text { Lugar de para onde } \\
\text { vai }\end{array}$ & Freqüência & $\%$ \\
\hline Residência & 1798 & $67,42 \%$ \\
\hline Trabalho & 472 & $17,70 \%$ \\
\hline Compras & 20 & $0,75 \%$ \\
\hline $\begin{array}{l}\text { Consultas médicas, } \\
\text { odontológicas }\end{array}$ & 19 & $0,71 \%$ \\
\hline Estudo & 65 & $2,44 \%$ \\
\hline Lazer & 7 & $0,26 \%$ \\
\hline Visita & 32 & $1,20 \%$ \\
\hline FTC & 82 & $3,07 \%$ \\
\hline UNIJORGE & 30 & $1,12 \%$ \\
\hline Outros & 142 & $5,32 \%$ \\
\hline & $\Sigma=2667^{8}$ & $\Sigma=100,00 \%$ \\
\hline${ }^{8}$ Total de questionários válidos. &
\end{tabular}

Observando as Tabelas 7 e 8, vale ressaltar o percentual de usuários que responderam a FTC como opção de origem $(2,89 \%)$ ou de destino $(3,07 \%)$, comprovando a existência de viagens internas geradas por este "cluster de atividades". Essas viagens ocorrem, pois 0063 onforme já citado anteriormente, a instituição de ensino superior FTC situa-se próxima ao Shopping Paralela, com possibilidade de acesso a pé. Além disso, ambos os empreendimentos estão localizados na via marginal da Avenida Paralela. No caso das viagens de automóvel, essas viagens podem ser realizadas sem o uso do sistema viário externo.

Conforme já mencionado anteriormente, o foco do estudo são as viagens por automóvel. Desta forma, buscou-se então verificar se os clientes que vinham ao shopping de automóvel trocavam de estacionamento ao se deslocarem da ou para a FTC. O objetivo dessa questão foi verificar o percentual que representaria o fator de atenuação nas viagens externas. Observou-se que $3,39 \%$ dos usuários entrevistados usam ambos os estacionamentos, do Shopping Paralela e da FTC (ver Tabela 9).

Tabela 9. Estacionamentos utilizados

\begin{tabular}{lcc}
\hline \multicolumn{1}{c}{ Opção } & Freqüência & $\%$ \\
\hline do shopping Paralela & 2387 & $90,97 \%$ \\
\hline da FTC $^{9}$ & 22 & $0,84 \%$ \\
\hline $\begin{array}{l}\text { Ambos - do shopping } \\
\text { Paralela e da FTC }\end{array}$ & 89 & $3,39 \%$ \\
\hline Outros $^{10}$ & 126 & $4,80 \%$ \\
\hline & $\Sigma=2624$ & $\Sigma=100,00 \%$ \\
\hline
\end{tabular}

${ }^{9}$ Esse valor se refere às entrevistas realizadas no Shopping Paralela, pois não foi possível realizar as entrevistas na FTC e assim realizar no estacionamento desse estabelecimento essa mesma questão.

${ }^{10}$ Denominam-se outros estacionamentos aqueles localizados em outras Instituições de Ensino Superior próximas, tais como Universidade Jorge Amado (UNIJORGE) ou logradouros públicos, mas que necessitam acessar as vias externas. Vale ainda ressaltar que os empreendimentos em estudo localizam-se numa via marginal onde não é permitido estacionar, porém, alguns entrevistados consideraram o estacionamento externo do shopping como rua.
Observou-se também, que $0,84 \%$ dos entrevistados afirmaram usar o estacionamento da FTC, mas é importante ressaltar que esse valor se refere às entrevistas realizadas no Shopping Paralela, pois não foi possível realizar entrevistas na FTC e assim aplicar no estacionamento desse estabelecimento essa mesma questão.

O valor médio do tempo de permanência do cliente no shopping center levantado na entrevista, o qual que representa também o tempo de permanência na vaga de estacionamento, foi de 1 hora e 45 minutos.

O questionário também buscou analisar as categorias de viagens. O resultado dessa análise mostrou que:

- 74,63\% das viagens foram exclusivas para o shopping;

- 19,37\% das viagens foram de usuários que decidiram ir ao shopping porque estavam em um local próximo;

- $6 \%$ das viagens foram de usuários que passaram em frente ao shopping e resolveram entrar. São viagens não desviadas, já existentes na via, onde a parada no shopping center não configurou uma alteração da rota. Esse percentual reflete também um comportamento já apontado pela administração do empreendimento, no qual alguns usuários costumam parar no shopping para esperar a melhora do engarrafamento na avenida em horários de pico.

Para se conhecer a freqüência de uso do sistema viário e com isso avaliar um possível impacto sobre esse sistema, foi perguntado se o usuário no seu trajeto normal de todos os dias utilizava a Avenida Luiz Viana Filho. O resultado mostrou que a maioria dos usuários $(70,69 \%)$ usa a avenida todos os dias.

\section{ANÁLISE COMPARATIVA}

Esta etapa do trabalho tem como objetivo realizar uma análise comparativa de dois estudos de caso: o caso de um PMGV localizado em Porto Alegre (shopping center + hipermercado) e o caso de um PMGV localizado em Salvador (shopping center + instituição de ensino superior). Essa técnica, denominada Estudos Comparativos de Casos, segue os passos do método comparativo, descrevendo, exemplificando, comparando por justaposição e comparação propriamente dita os fenômenos que interessam ao pesquisador.

É importante esclarecer que em ambos os casos utilizou-se a técnica de questionários com perguntas diretas para obter as informações que serviram de base para as análises, levantando-se dados socioeconômicos e informações referentes às viagens. A Tabela 10 apresenta um resumo dos principais aspectos contidos nos dois questionários aplicados.

O percentual de condutores observado em Porto A- 
Tabela 10. Estudo Comparativo de Casos - Características das Viagens de PMGVs

\begin{tabular}{|c|c|c|}
\hline & PORTO ALEGRE & SALVADOR \\
\hline Tipo de PMGV & $\begin{array}{c}\text { Shopping Center + } \\
\text { Hipermercado }\end{array}$ & $\begin{array}{c}\text { Shopping Center + } \\
\text { Instituição de Ensino }\end{array}$ \\
\hline \multicolumn{3}{|l|}{ Tipo de Usuário } \\
\hline Condutor & $91,76 \%$ & $75,01 \%$ \\
\hline Carona & $8,24 \%$ & $24,99 \%$ \\
\hline \multicolumn{3}{|c|}{ Origem da Viagem $^{11}$} \\
\hline Residência & $47,84 \%$ & $50,11 \%$ \\
\hline Trabalho & $32,16 \%$ & $32,16 \%$ \\
\hline \multicolumn{3}{|c|}{ Destino da Viagem } \\
\hline Residência & $56,47 \%$ & $67,42 \%$ \\
\hline Trabalho & $23,53 \%$ & $17,70 \%$ \\
\hline \multicolumn{3}{|c|}{ Área de Influência - Isócrona } \\
\hline & $<=10$ minutos & 15 a 30 minutos \\
\hline \multicolumn{3}{|c|}{ Tempo Médio de Viagem de Acesso ao Shopping } \\
\hline & 17,16 minutos & 22 minutos \\
\hline \multicolumn{3}{|c|}{ Estacionamento Utilizado } \\
\hline Shopping & $88,10 \%$ & $90,97 \%$ \\
\hline Hipermercado & não informado & - \\
\hline Faculdade & - & 0,84 \\
\hline Ambos $^{12}$ & $1,19 \%$ & $3.39 \%$ \\
\hline Rua & $10,71 \%$ & $4,8 \%{ }^{13}$ \\
\hline \multicolumn{3}{|c|}{ Tempo Médio de Permanência no Estacionamento do Shopping } \\
\hline & 1h e $33 \mathrm{~min}$ & $1 \mathrm{~h} 46 \mathrm{~min}$ \\
\hline
\end{tabular}

legre é maior que o de Salvador. Isso pode ser explicado em função do tipo das atividades dos PMGVs estudados. O Estabelecimento de Ensino Superior, a FTC, pode ter exercido uma forte influência no número dos usuários do tipo carona.

Outro aspecto que merece destaque nessa análise comparativa se refere à Área de Influência Direta (AID) dos PMGVs. Conforme pode ser observado por meio das informações sobre as isócronas e do tempo médio de acesso ao shopping, o caso de Salvador induz à interpretação que a instituição de ensino superior pode ter influenciado na diversidade das localidades de origem e destino das viagens, aumentando o alcance de atração de viagens do shopping. Entretanto, deve-se ressaltar que, ao se limitar a área de influência, pelo traçado das isócronas (ou das isócotas), são considerados vários fatores que podem influenciar no poder de atração do empreendimento, tais como polarização do local, condições e formas de acesso e tempo de percurso.

$\mathrm{Na}$ análise do comportamento do uso dos estacionamentos, o que determinará o fator de atenuação do impacto no sistema viário do entorno do PMGV, pode-se observar que os valores encontrados para $O$ uso em ambos os estacionamentos são baixos $(1,19 \%$ no estudo de caso de Porto Alegre e 3,39\% no estudo de caso de Salvador). Esses valores podem ser explicados pela relativa facilidade de acesso a pé, pela dupla co- brança como observado no caso de Porto Alegre ou pelas características do sistema viário, no caso de Salvador, em que o sentido único de direção da via marginal de acesso aos dois empreendimentos dificulta a troca de estacionamentos, possibilitando apenas que o usuário utilize primeiro o estacionamento do shopping e depois o da FTC, mas não no sentido inverso.

Uma última e importante análise com relação aos estacionamentos deve ser ressaltada: a existência de estacionamento na via pública. No caso de Porto Alegre, esse número foi significativo $(10,71 \%)$ e pode representar um fator de impacto negativo para o sistema viário no entorno do PMGV pesquisado.

\section{CONCLUSÕES}

Conforme se pode observar a partir dos resultados dos estudos de caso realizados, uma parcela dos usuários de um PMGV utiliza uma única viagem para visitar os diversos empreendimentos do complexo. Quando esses clientes realizam a viagem por automóvel, uma parcela pequena também troca de estacionamento ao visitar os estabelecimentos que formam o "cluster de atividades".

Embora, neste trabalho, os percentuais observados para o uso de ambos os estacionamentos sejam relativamente pequenos em relação ao total de viagens ao PMGVs (1,19\% para o estudo de caso de Porto Alegre 
e 3, 39\% para o estudo de caso em Salvador), eles confirmam que existem viagens internas e isso serve para sinalizar a importância de se investir em pesquisas mais aprofundadas, dirigidas a identificar o percentual dessas viagens internas, pois esse valor pode representar o fator de atenuação do número de viagens realizadas (caso de uso de mais de um estacionamento) ou aumentar esse número (no caso de estacionamento na via), o que ocasionará agravamento do impacto que esse tipo de pólo gera no sistema viário.

Considera-se também, em caráter preliminar, que o grau de integração espacial das atividades no interior do cluster condicionará a facilidade de acesso a pé dos usuários, podendo favorecer a interação das viagens internas não motorizadas, atenuando as motorizadas.

Os estudos de caso apresentados neste trabalho representam um embrião para o tipo de pesquisa que busca iniciar discussões sobre o comportamento das viagens em PMGVs brasileiros e apresentar os primeiros parâmetros para o estabelecimento dos fatores de atenuação das viagens que possam ser utilizados em estudo de avaliação de impactos desses empreendimentos no sistema viário. Com isso, espera-se auxiliar nos estudos de planejamento de transportes, oferecendo subsídios para uma previsão mais adequada e realista dos impactos gerados pelos PMGVs, contribuindo para a otimização dos espaços urbanos e para uma melhor mobilidade para a população.

\section{AGRADECIMENTOS}

Ao $\mathrm{CNPq}$ pelo apoio à Rede Ibero Americana de Estudos em Pólos Geradores de Viagens - Rede PGV (http://redpgv.coppe.ufrj.br). Aos membros da Rede PGV pela sua dedicação e compromisso com a produção e divulgação do conhecimento, fundamentais para fortalecer e garantir a manutenção deste projeto coletivo. À FAPESB pelo apoio no fornecimento da bolsa de mestrado, que possibilita dedicação exclusiva ao Mestrado de Engenharia Ambiental Urbana (MEAU/UFBA).

\section{REFERÊNCIAS BIBLIOGRÁFICAS}

Bochner, B.S.; Hooper, K. \& Sperry, B. (2010) Improved Estimation of internal trip capture for mixed-use developments, ITE Journal, August.

Colorado/Wyoming Section Technical Committee - Trip Generation (1987) Trip Generation for Mixed-Use Developments, ITE Journal, February.

Datta, T.K, Datta, S. \& Nannapaneni P. (1998) Trip Generation Models for Multiuse Highway Commercial Developments, ITE Journal, February.

Datta, T.K. \& Schattler, K.L. (2010) Trip Generation: Advanced concepts and applications; Student Supplement, Institute of Transportation Engineers Education Foundation INC.

Freitas I. M. D. P. \& Santos, D. V. C. (2010) Estudo de pólos múltiplos geradores de viagens: o caso do shopping Paralela, relatório de pesquisa, Mestrado em Engenharia Ambiental Urbana, Universidade Federal da Bahia, Salvador - BA.

Goldner L.G. \& Schmitz, A. (2010) Estudo de pólos múltiplos geradores de viagens: $\mathrm{O}$ caso do parque Montigalá em Barcelona, XVI Congresso Pan-Americano de Engenharia de Tráfego e Transportes e Logística, Lisboa, Portugal, Julho.

Goldner L.G. \& Westphal, D. (2010) Estudo dos pólos múltiplos geradores de viagens: o caso do Iguatemi - POA, relatório de pesquisa, Departamento de Engenharia Civil, Universidade Federal de Santa Catarina, Florianópolis - SC.

Institute of Transportation Engineers, (2004) Trip Generation Handbook.
Institute of Transportation Engineers, (2008) Trip Generation, $8^{\text {th }}$ Edition. Rede Ibero-americana de Estudos em Pólos Geradores de Viagens - Rede PGV, disponível na internet em <http://redpgv.coppe.ufrj.br>, acesso em outubro de 2010 . 